\title{
Autistic traits are associated with the functional connectivity of between- but not within-attention systems in the general population
}

Sayaka Yoshimura ${ }^{*} \mathbb{0}$, Kei Kobayashi ${ }^{2}$, Tsukasa Ueno ${ }^{2}$, Takashi Miyagi ${ }^{2}$, Naoya Oishi ${ }^{3}$, Toshiya Murai ${ }^{2}$ and Hironobu Fujiwara ${ }^{2,4}$

\begin{abstract}
Background: Previous studies have demonstrated that individuals with autism spectrum disorder (ASD) exhibit dysfunction in the three attention systems (i.e., alerting, orienting, and executive control) as well as atypical relationships among these systems. Additionally, other studies have reported that individuals with subclinical but high levels of autistic traits show similar attentional tendencies to those observed in ASD. Based on these findings, it was hypothesized that autistic traits would affect the functions and relationships of the three attention systems in a general population. Resting-state functional magnetic resonance imaging (fMRI) was performed in 119 healthy adults to investigate relationships between autistic traits and within- and between-system functional connectivity (FC) among the three attention systems. Twenty-six regions of interest that were defined as components of the three attention systems by a previous task-based fMRI study were examined in terms of within- and between-system FC. We assessed autistic traits using the Autism-Spectrum Quotient.
\end{abstract}

Results: Correlational analyses revealed that autistic traits were significantly correlated with between-system FC, but not with within-system FC.

Conclusions: Our results imply that a high autistic trait level, even when subclinical, is associated with the way the three attention systems interact.

Keyword: Attention, Attention network, Autistic traits, Resting-state functional magnetic resonance imaging, Functional connectivity

\section{Background}

When the process of attention is applied to manage competing environmental information, the result is bias selection and action toward one choice while separating out interference from the remaining information [3]. Thus, attention is a primary component of cognition that

\footnotetext{
*Correspondence: yoshimurasayaka@gmail.com

1 Faculty of Human Health Science, Graduate School of Medicine, Kyoto University, 53 Shogoin-Kawaharacho, Sakyo-Ku, Kyoto 606-8507, Japan Full list of author information is available at the end of the article
}

allows humans to experience the world and that influences perception, memory, behavior and, possibly, the direction of brain development.

Attention is thought to be composed of three anatomically and functionally independent systems: the alerting system (alerting), the orienting system (orienting), and the executive control system (EC; for a review, see [54]). Alerting is the most elementary aspect of attention and is the system responsible for achieving and maintaining a state of sensitivity to incoming information. Orienting is associated with the ability to assign priority to

(c) The Author(s) 2020. This article is licensed under a Creative Commons Attribution 4.0 International License, which permits use, sharing, adaptation, distribution and reproduction in any medium or format, as long as you give appropriate credit to the original author(s) and the source, provide a link to the Creative Commons licence, and indicate if changes were made. The images or other third party material in this article are included in the article's Creative Commons licence, unless indicated otherwise in a credit line to the material. If material is not included in the article's Creative Commons licence and your intended use is not permitted by statutory regulation or exceeds the permitted use, you will need to obtain permission directly from the copyright holder. To view a copy of this licence, visit http://creativeco mmons.org/licenses/by/4.0/. The Creative Commons Public Domain Dedication waiver (http://creativecommons.org/publicdomain/ zero/1.0/) applies to the data made available in this article, unless otherwise stated in a credit line to the data. 
sensory inputs by selecting a location or sensory modality [49]. EC is a multidimensional and relatively complex system that includes mental operations, such as divided attention and detecting and resolving conflicts, that are responsible for controlling behaviors and thoughts. These three systems work more efficiently when interacting with each other [13, 24, 67].

Previous studies have reported that individuals with autism spectrum disorder (ASD) exhibit attentional dysfunction in all three systems (for a review, see [36]). ASD is a neurodevelopmental disorder characterized by deficits in social interaction and the presence of repetitive and restricted behaviors [2]. From early childhood, individuals with ASD have pervasive abnormalities in attention [1] that could influence the development of the two aforementioned diagnostic features of ASD. In particular, impairments in orienting have been consistently reported in behavioral and imaging studies [6,36,37].

Furthermore, other behavioral and imaging studies have reported that the relationships among the three attention systems in individuals with ASD are different to those in neurotypical individuals. For example, a behavioral study found that the pattern of the relationship between alerting and EC in adolescents with ASD differs from that in typically developing adolescents [35]. Similarly, a resting-state fMRI study revealed differences in the temporal dynamics from orienting to EC between ASD and typically developing individuals [10].

It is also possible that the presence of autistic traits in people in the general population may affect attention, including functional relationships among the three attention systems in which there are strong individual differences (e.g., [22]). Autistic traits are continuously distributed throughout the general population and range from individuals with almost no autistic traits to severely impaired and diagnosed individuals (e.g., [14]). Several behavioral studies have reported that individuals with subclinical but high levels of autistic traits exhibit attentional tendencies that are similar to those observed in ASD when compared to individuals with fewer autistic features (e.g., [47, 69]).

Additionally, imaging studies have demonstrated that autistic traits are dimensionally related to functional connectivity (FC) in neurotypical individuals. For example, FC of the social processing network is negatively related to autistic traits in typically developing adults [18]. Another study found that whole-brain FC is highest in controls, intermediate in the unaffected siblings of individuals with ASD, and lowest in individuals with ASD [44]. Taken together, these findings indicate that autistic traits in the general population might be associated with FC between regions that are responsible for the same (i.e., within-system) or two different (i.e., between-system) attention systems. However, to the best of our knowledge, no studies have examined these relationships in the general population.

Thus, the primary aim of the present study was to investigate the relationship between autistic traits in a general population and within-and between-system FC among brain areas that have been reported as components of the alerting, orienting, and EC networks [23].

\section{Results \\ Psychological data}

The mean \pm standard deviation $(S D)$ of the AutismSpectrum Quotient (AQ) scores in the present study was $18.4 \pm 8.0$, which was identical to the value observed in a study of the general population assessed using the Japanese version of the AQ [64]. Kolmogorov-Smirnov tests revealed that the AQ scores had normal distributions $(p=0.20$; Fig. 1).

\section{Relationships between $\mathrm{AQ}$ scores and FC}

Correlation analyses revealed significant relationships between the AQ scores and the between-system FC values (Table 1 and Fig. 2). In contrast, there were no significant associations between the AQ scores and the within-system FC values. To investigate gender differences in the relationships between autistic traits and the FC values, we assessed possible correlations between the $\mathrm{AQ}$ scores and the within- and between FC values with age as the only covariate. The results were essentially the same as those obtained after using both age and gender as covariates (Additional file 1: Table S1).

\section{Discussion}

The primary goal of the present study was to examine whether autistic traits in a general population would be associated with within- and/or between-system FC among the three attentional systems, i.e., the alerting, orienting, and EC systems. There were significant associations between AQ scores and between-system FC values but not between AQ scores and within-system FC values; the AQ scores had positive relationships with FC between the regions responsible for alerting and orienting and with FC between the regions responsible for orienting and EC, but a negative relationship with FC between the regions responsible for alerting and EC.

In the present study, a greater degree of autistic tendencies was related to stronger FC between the thalamus, which is the center of alerting, and the fusiform gyrus responsible for orienting (i.e., the fusiform face area [FFA]). Previous studies have consistently reported that orienting is impaired in individuals with ASD (for a review, see [36]) and that this function is weaker in individuals with a high level of autistic traits from a general 


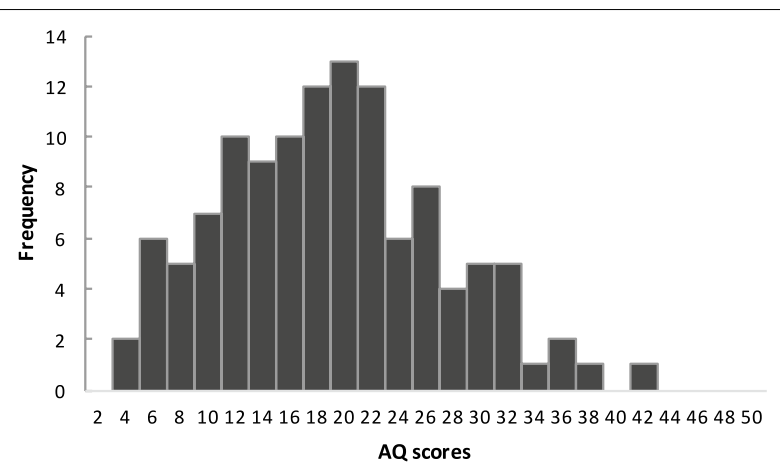

Fig. 1 Distribution of the AQ scores

population $[47,69]$. Alerting, or the function of achieving and maintaining a state of sensitivity to incoming information, promotes orienting [13, 28, 59]. Thus, the present findings that there was stronger $\mathrm{FC}$ between alerting and orienting in individuals with higher levels of autistic traits suggest that the weaker function in orienting might be compensated for by alerting.

Table 1 The two ROls that exhibited significant relationships between $A Q$ scores and FC values

\begin{tabular}{|c|c|c|c|}
\hline & T-value & $\begin{array}{l}\text { FDR } \\
\text { adjusted } \\
p \text {-value }\end{array}$ & $r$ \\
\hline \multicolumn{4}{|l|}{ Alerting-Orienting } \\
\hline L. thalamus-R. fusiform gyrus & 3.42 & 0.021 & 0.30 \\
\hline \multicolumn{4}{|l|}{ Alerting-Executive control } \\
\hline Cerebeller vermis-L. fusiform gyrus & -3.37 & 0.026 & 0.30 \\
\hline Cerebeller vermis-R. inferior frontal gyrus & -3.48 & 0.013 & 0.31 \\
\hline \multicolumn{4}{|l|}{ Orienting-Executive control } \\
\hline L. precentral gyrus-L. inferior frontal gyrus & 3.46 & 0.019 & 0.31 \\
\hline
\end{tabular}

$\mathrm{L}=$ Left; $\mathrm{R}=$ Right; $\mathrm{AQ}=$ Autism-spectrum quotient; $\mathrm{ROI}=$ Regions of interests

Based on evidence showing that the FFA is an important factor in those with ASD and asymptomatic individuals with higher levels of autistic traits, the notion that this region presents a weaker function in orienting is reasonable. The FFA is known to be specialized for face perception (e.g., [34]). Individuals with ASD exhibit impairments in face perception (for a review, see [65]) and a functionally and structurally atypical FFA [20, 50, 57, 63]. Additionally, a positron emission tomography (PET) scan study revealed that cholinergic deficits in the fusiform gyrus, which are related to impairments in social interaction, are evident in subjects with ASD [60]. Because the orienting system, but not the other attention systems, is cholinergic [49], these findings suggest that orienting deficits in individuals with ASD might be partly due to differences in the FFA and that higher levels of autistic traits might be associated with more deficient orienting. Because individuals with subclinical but high levels of autistic traits also exhibit diminished activation in the fusiform gyrus during a face recognition task [16], people with higher levels of autistic traits might have a weaker orienting function that is related to alterations in the FFA.

The weaker orienting function, associated with autistic traits, could also have impacted FC between orienting and EC. The present results revealed that a greater degree of autistic tendencies was related to stronger connectivity between the precentral gyrus (orienting) and the inferior frontal gyrus (IFG; EC). The function of the precentral gyrus in orienting is thought to be similar to that of the frontal eye field [23], which implements eye movements such as saccades. Saccades are the phenomenon of initiating rapid ballistic shifts in eye gaze that are needed for attentional shifts during the orienting process [5]. Several studies have reported that saccades are impaired in individuals with ASD (for a review, see [43]). Moreover,

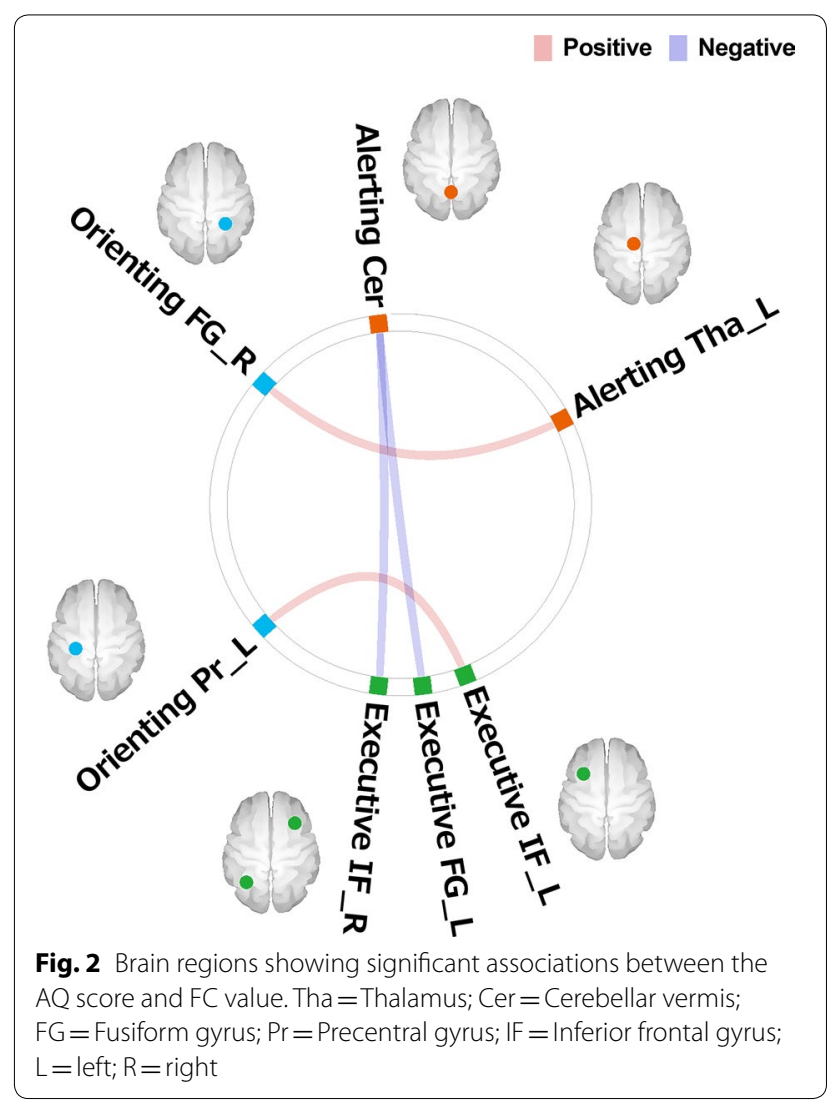


because saccades are also impaired in unaffected firstdegree relatives of individuals with ASD [42], those with a greater degree of autistic traits might have weaker saccade function. On the other hand, Kane et al. [33] found that people with higher levels of executive function perform better on a saccade task than those with lower levels of executive function, which suggests that EC improves the function of saccades. Taken together with functions related to the IFG, which involves the selection of information to adjust sensory inputs $[7,68]$, the present results suggest that weaker saccade function in individuals with higher levels of autistic traits might be compensated for by EC.

In the present study, a greater degree of autistic tendencies was also related to weaker FC between the cerebellar vermis (alerting) and the two $\mathrm{EC}$ regions, i.e., the fusiform gyrus (as mentioned in the Methods section, this region is regarded as a non-face area) and the IFG. This finding may indicate that there is a delayed development of the alerting-EC relationship in individuals with a greater degree of autistic tendencies. In general, relative to alerting and orienting, EC follows a protracted development period that can persist through adolescence (for reviews, see $[11,19])$. During that developmental course, while functional interactions among the attentional systems (except the alerting and EC interactions) are characterized in childhood and persist into adulthood, the direction of the alerting-EC interaction is generally reversed by 12 years of age such that the positive association in childhood changes into a negative one during adolescence $[45,53]$. On the other hand, a behavioral study examining the interactions among the attention systems found that there is a positive association between alerting and EC in adolescents with ASD [35] whereas typically developing adolescents have a negative association [27] or lack an association [35]. Considering that adults with ASD do not exhibit an alerting-EC association [25] and that EC skills mature at a slower pace in ASD individuals than typically developing people (for a review, see [17]), the findings in previous behavioral studies suggest that the functional reversal of the alerting-EC association may be delayed in ASD and that the development of this association in adults with ASD may be in a stage equivalent to that observed in typically developing adolescents. Moreover, together with the idea that age-related changes in the interactions of attentional behaviors are associated with changes in FC [55] and findings about age being an important factor to consider when assessing FC alterations in ASD $[32,46]$, it is likely that individuals with ASD show delayed or different patterns of developmental changes in FC between alerting and EC. The present results showing that higher levels of autistic tendencies were related to weaker FC between alerting and
EC may indicate that this type of atypical development also occurs in non-clinical individuals with high levels of autistic traits.

The present findings also have clinical implications regarding the mental health of non-clinical individuals with higher levels of autistic traits. A considerable number of studies have documented higher rates of psychiatric problems, such as anxiety and depression, in this non-clinical population (e.g., [41, 51, 66]); these issues could be derived, at least in part, from orienting dysfunction. In other words, these disorders could be due to attention biases, such as reduced attention to positive information, excessive attention to negative information, and local processing biases; such kinds of biases could induce a distressed mood $[4,12,29,58]$. Because this type of orienting dysfunction has been reported in non-clinical individuals with higher levels of autistic traits $[39,56]$, it may be a cause of the elevated rates of other psychiatric conditions in this population. Moreover, if alerting and EC compensate for orienting in this population, as suggested by the present findings, then training alerting and EC functions might result in maintenance of mental health through functional improvements in orienting. The function of attention networks, especially that of EC, can be improved by changes in brain states induced by exercise [21,31] or meditation [61]. Thus, investigations on the association between training attentional functions (through these activities) and mental health in this population would likely to provide interesting results.

The present study has several limitations that should be noted. First, the present findings are limited by the age of the participants. As described above, it is possible that the directions of the interactions among the attention systems might be partly reversed with increasing age. Future research using elderly populations will clarify whether this functional reverse might happen and/or when it does. Second, the relationships between actual attentional functions and the between-system FC of attention networks were not assessed in the present study. Although resting-state brain networks resemble task-evoked networks [62], the relationships among the three attention systems (i.e., between-system FC) might change during active attention. Therefore, task-dependent FC should be studied using a combination of imaging and behavioral data to reveal possible changes in the relationships among active attention systems and in relation to the presence of compensatory mechanisms. Third, future investigations should consider within-system FC. In the present study, autistic traits were not associated with within-system FC whereas stronger and weaker FC within orienting have been reported in individuals with ASD [26, 37]. It is possible that the present results were influenced by the non-clinical nature of the participants 
or the relatively small sample size. Thus, studies with larger sample sizes should be conducted to determine whether autistic traits in the general population are associated with within-system FC.

\section{Conclusion}

This study demonstrated that autistic traits in the general population were associated with between-system FC among the neural substrates of the three attention systems. These results suggest that autistic traits affect relationships among the three systems and could possibly induce changes in the efficiency of attention. Although further research is necessary, the present study provided novel insights into the individual differences associated with attentional functions.

\section{Methods \\ Participants}

This study was conducted as part of a project investigating the association between personalized values and lifestyle habits. The participants included 119 healthy volunteers ( 45 females, mean age $\pm S D: 36.2 \pm 14.3$ years) who were confirmed as right-handed using the Edinburgh Handedness Inventory [48]. Interviews conducted by two well-trained psychiatrists confirmed that none of the participants had any type of psychiatric disorder, severe medical or neurological illness, or severe head injury. The IQ scores of the participants were estimated with the Japanese version of the Adult Reading Test (JART; [40]); all participants fell within the normal range (full-scale IQ, $M=109.5, S D=6.4$; verbal IQ, $M=111.0, S D=7.4$; and performance IQ, $M=106.3, S D=4.9$ ). After having the experimental procedures fully explained, all participants provided written informed consent prior to participation in the study.

\section{Psychological questionnaire}

The AQ is a self-report and one of the most commonly used questionnaires assessing the degree of autistic traits in an individual [8]. Its reliability and validity have been tested and confirmed in many studies from various countries (e.g., $[8,38,64])$. The measure consists of 50 items that are each scored as 1 point if the respondent records mild or strong abnormal or autistic-like behaviors; thus, a higher AQ score is indicative of a higher degree of autistic traits. We used the Japanese version of the AQ [64] in this study.

\section{MRI acquisition}

Image scanning was conducted with a single-shot gradient echo planar imaging (EPI) pulse sequence on a 3-T
MRI unit (Tim-Trio, Siemens, Erlangen, Germany) with a $40-\mathrm{mT} / \mathrm{m}$ gradient, a receiver-only 32 -channel phasedarray head coil, and small elastic pads placed on both sides of the head to minimize head motion. Structural MRI data were acquired using three-dimensional magnetization-prepared rapid gradient echo (3D-MPRAGE) sequences with the following parameters: repetition time (TR), $2000 \mathrm{~ms}$; echo time (TE), $3.4 \mathrm{~ms}$; inversion time, $990 \mathrm{~ms}$; field of view (FOV), $225 \times 240 \mathrm{~mm}$; matrix size, $240 \times 256$; resolution, $0.9375 \times 0.9375 \times 1.0 \mathrm{~mm}^{3}$; and 208 total axial sections without intersection gaps. We instructed the participants to visually concentrate on a fixation cross in the center of the screen and to avoid thinking about anything specific. Functional images were obtained during a single 10-min session, while the subjects kept their eyes open, and using a sequence with the following characteristics: TR, $2500 \mathrm{~ms}$; TE, $30 \mathrm{~ms}$; flip angle, $80^{\circ}$; FOV, $212 \times 212 \mathrm{~mm}$; matrix size, $64 \times 64$; inplane spatial resolution, $3.3125 \times 3.3125 \mathrm{~mm}^{2}$; 40 total axial slices; and slice thickness, $3.2 \mathrm{~mm}$ with $0.8 \mathrm{~mm}$ gaps in ascending order. A dual-echo gradient echo dataset for B0 field mapping was also acquired for distortion correction purposes. After the scanning, the subjects were asked questions about sleepiness during data acquisition. We recorded only answers denying sleep (no "fell asleep" or "was almost asleep" replies).

\section{Image processing}

The resting state-fMRI dataset was corrected for EPI distortions in the FSL software package (FMRIB's software library ver. 5.0.9; http://www.fmrib.ox.ac.uk/fsl) using FMRIB's Utility for Geometrically Unwarping EPIs (FUGUE), which unwarps EPI images based on fieldmap data. Subsequently, artifact components and motionrelated fluctuations were removed from the images using FMRIB's independent component analysis-based $\mathrm{X}$-noiseifier [30].

We performed all imaging and statistical analyses using the CONN-fMRI Functional Connectivity toolbox (ver.17e; www.nitrc.org/projects/conn) with the statistical parametric mapping package (SPM12; http://www. fil.ion.ucl.ac.uk/spm). First, all functional images were realigned and unwarped, slice-timing corrected, co-registered with structural data, spatially normalized into the standard MNI space (Montreal Neurological Institute, Montreal, QC, Canada), outlier-detected (ART-based scrubbing), and smoothed using a Gaussian kernel of $8 \mathrm{~mm}$ full width at half maximum.

All preprocessing steps were performed using a default preprocessing pipeline for volume-based analysis (to MNI space). We segmented structural data into gray matter, white matter, and cerebrospinal fluid (CSF), and then normalized them in the same default preprocessing 
pipeline. The principal components of the signals from white matter and CSF and the translational and rotational movement parameters (with six other parameters representing their first-order temporal derivatives) were removed with a covariate regression analysis conducted using CONN. Using the implemented CompCor strategy [9], we reduced the effects of nuisance covariates, including fluctuations in resting-state fMRI signals from white matter, CSF, and their derivatives as well as realignment parameter noise. As recommended, band-pass filtering was performed with a frequency window of $0.008-$ $0.09 \mathrm{~Hz}$, this preprocessing step was found to increase the retest reliability.

\section{FC analysis}

We conducted a region of interest (ROI)-to-ROI FC analysis in the present study. We specified 26 spherical clusters with $10-\mathrm{mm}$ diameters and peak coordinates, as described in Fan et al. [23]. These authors conducted a task-based fMRI study that identified these regions as components of the three attention systems. Table 2 shows the ROIs in each system (coordinates are quoted in the Talairach space). Although each of the three systems includes the fusiform gyrus, the regions responsible for orienting were distinguished as the FFA and were differentiated from the regions responsible for alerting and EC. The alerting and EC regions were located outside of the boundary of the FFA: the right FFA had an average size of $1 \mathrm{~cm}^{3}$ and was located at the Talairach coordinates $40 \mathrm{x},-55 \mathrm{y}$, and $-10 \mathrm{z}$; the left FFA had an average size of $0.5 \mathrm{~cm}^{3}$ and was located at the Talairach coordinates $-35 \mathrm{x},-63 \mathrm{y}$, and $-10 \mathrm{z}$ [34].

The regions responsible for alerting included the thalamus, parietal regions (e.g., temporoparietal junction), and the mid-frontal gyrus. The regions responsible for orienting included the superior parietal cortex and the frontal eye field. The orienting regions are roughly equivalent to the dorsal attention network in large-scale brain networks [15]. The EC regions included the anterior cingulate cortex and the dorsolateral prefrontal cortex, which overlaps with the front-parietal network and with the salience network in large-scale brain networks [52].

\section{Statistical analysis}

We assessed the associations between the AQ scores and the within-and between-system FC values of the two ROIs using $t$-statistics by CONN with age and gender as covariates; we considered all false discovery rate-corrected $p$-values $<0.05$ as statistically significant.

\section{Supplementary information}

Supplementary information accompanies this paper at https://doi. org/10.1186/s12868-020-00603-2.
Table 2 Brain regions supporting the three attentional networks

\begin{tabular}{|c|c|c|c|c|c|}
\hline \multirow[t]{2}{*}{ Network } & \multirow[t]{2}{*}{ Brain region } & \multirow[t]{2}{*}{ BA } & \multicolumn{3}{|c|}{ Coordinates } \\
\hline & & & $x$ & $y$ & $z$ \\
\hline \multirow[t]{9}{*}{ Alerting } & R. superior temporal gyrus ${ }^{\mathrm{a}}$ & 22 & 61 & -40 & 11 \\
\hline & Superior colliculus & & 6 & -28 & -7 \\
\hline & L. Thalamus & & -12 & -17 & 6 \\
\hline & R. thalamus & & 13 & -9 & 7 \\
\hline & L. inferior parietal lobe & 40 & -50 & -20 & 21 \\
\hline & L. fusiform gyrus & 37 & -42 & -62 & 0 \\
\hline & L. inferior frontal gyrus & 47 & -32 & 27 & 0 \\
\hline & Cerebellar vermis & & 0 & -65 & -10 \\
\hline & L. superior parietal lobe ${ }^{b}$ & 7 & -36 & -46 & 50 \\
\hline \multirow[t]{8}{*}{ Orienting } & L. fusiform gyrus & 37 & -34 & -60 & -5 \\
\hline & R. fusiform gyrus & 37 & 30 & -47 & -6 \\
\hline & L. precentral gyrus ${ }^{c}$ & 6 & -38 & -8 & 41 \\
\hline & R. superior parietal lobe ${ }^{d}$ & 7 & 32 & -41 & 30 \\
\hline & L. superior frontal gyrus & 6 & -10 & 7 & 57 \\
\hline & L. superior parietal lobe $e^{e}$ & 7 & -28 & -72 & 28 \\
\hline & R. postcentral gyrus & 2 & 57 & -21 & 43 \\
\hline & L. precentral gyrus & 4 & -30 & -26 & 53 \\
\hline \multirow[t]{9}{*}{ Executive control } & Thalamus ${ }^{f}$ & & -22 & -27 & 3 \\
\hline & L. superior frontal gyrus ${ }^{c}$ & 6 & -16 & 4 & 44 \\
\hline & R. inferior frontal gyrus & 45 & 36 & 26 & 15 \\
\hline & L. fusiform gyrus & 37 & -36 & -60 & 1 \\
\hline & L. inferior frontal gyrus & 47 & -34 & 20 & 5 \\
\hline & Cerebellar vermis & & 0 & -62 & -32 \\
\hline & R. middle frontal gyrus & 6 & 36 & -5 & 50 \\
\hline & R. fusiform gyrus & 37 & 44 & -58 & 1 \\
\hline & R. anterior cingulate gyrus & 32 & 6 & 36 & 26 \\
\hline
\end{tabular}

$\mathrm{L}=$ Left; $\mathrm{R}=$ Right; $\mathrm{BA}=$ Brodmann's area

a Subregion of temporal parietal junction

b Anterior intraparietal sulcus

c Close to frontal eye field

d Anterior intraparietal sulcus

e Junction of intraparietal and transverse occipital sulcus

Additional file 1: Table S1. The two ROls that exhibited significant relationships between $\mathrm{AQ}$ scores and FC values.

\section{Acknowledgements}

The authors thank all individuals who participated in the present study.

\section{Authors' contributions}

SY conceived the idea, designed and conducted the experiments, and drafted the manuscript. HF, TM2, and SY contributed to the conception of the study, interpretation of data, and revisions for critically important intellectual content. KK, TU, TM1, and NO contributed to the design and data acquisition, interpretation of data, and drafting the manuscript. All authors approved the final manuscript for submission and agree to be accountable for all aspects of the work, including the assurance that questions related to the accuracy or integrity of any part are appropriately investigated and resolved. All authors read and approved the final manuscript. 


\section{Funding}

This study was funded by a Grant-in-Aid for Scientific Research on Innovative Areas (Ministry of Education, Culture Sports, Science and Technology, Japan, Project Numbers: 16H06402, 16H06395, and 16H06397), Grant-in-Aid for Scientific Research (C; Japan Society for The Promotion of Science, 16K01790), Daiwa Securities Health Foundation, the Nakatomi Foundation, and the Impulsing Paradigm Change through Disruptive Technologies (ImPACT) Program of the Council for Science, Technology and Innovation (Cabinet Office, Government of Japan, 2015-PM11-08-01)

\section{Availability of data and materials}

The datasets generated and/or analyzed during the current study are not publicly available because we did not obtain the consent of participants to provide the datasets to third parties.

\section{Ethics approval and consent to participate}

The Ethics Committee of Kyoto University Graduate School and Faculty of Medicine approved this study (R0879), which we conducted in accordance with the guidelines of the Declaration of Helsinki. All participants provided written informed consent prior to participating in the study.

\section{Consent for publication}

Not applicable.

\section{Competing interests}

The authors declare that they have no competing interests.

\section{Author details}

${ }^{1}$ Faculty of Human Health Science, Graduate School of Medicine, Kyoto University, 53 Shogoin-Kawaharacho, Sakyo-Ku, Kyoto 606-8507, Japan. ${ }^{2}$ Department of Neuropsychiatry, Graduate School of Medicine, Kyoto University, 54 Shogoin-Kawaharacho, Sakyo-Ku, Kyoto 606-8507, Japan. ${ }^{3}$ Medical Innovation Center, Graduate School of Medicine, Kyoto University, 54 Shogoin-Kawaharacho, Sakyo-Ku, Kyoto 606-8507, Japan. ${ }^{4}$ RIKEN Center for Advanced Intelligence Project, Artificial Intelligence Ethics and Society Team, Nihonbashi 1-chome Mitsui Building, 15th floor, 1-4-1 Nihonbashi, Chuo-Ku, Tokyo 103-0027, Japan.

\section{Received: 25 August 2020 Accepted: 16 November 2020} Published online: 23 November 2020

\section{References}

1. Allen $G$, Courchesne E. Attention function and dysfunction in autism. Front Biosci. 2001;6:D105-19.

2. American Psychiatric Association. Diagnostic and statistical manual of mental disorders. 5th ed. Arlington: American Psychiatric Association; 2013.

3. Amso D, Scerif $G$. The attentive brain: insights from developmental cognitive neuroscience. Nat Rev Neurosci. 2015;16:606-19.

4. Armstrong T, Olatunji BO. Eye tracking of attention in the affective disorders: a meta-analytic review and synthesis. Clin Psychol Rev. 2012;32:704-23.

5. Awh E, Armstrong KM, Moore T. Visual and oculomotor selection: links, causes and implications for spatial attention. Trends Cogn Sci. 2006;10:124-30.

6. Barbaro J, Dissanayake C. Autism spectrum disorders in infancy and toddlerhood: a review of the ecidence on early signs, early identification tools, and early diagnosis. J Dev Behav Pediatr. 2009;30:447-59.

7. Barbas H, Zikopoulos B, Timbie C. Sensory pathways and emotional context for action in primate prefrontal cortex. Biol Psychiatry. 2011;69:1133-9.

8. Baron-Cohen S, Wheelwright S, Skinner R, Martin J, Clubley E. The autism-spectrum quotient (AQ): evidence from Asperger syndrome/highfunctioning autism, males and females, scientists and mathematicians. J Autism Dev Disord. 2001;31:5-17.

9. Behzadi Y, Restom K, Liau J, Liu TT. A component based noise correction method (CompCor) for BOLD and perfusion based fMRI. Neuroimage. 2007:37:90-101.
10. Bernas A, Barendse EM, Aldenkamp AP, Backes WH, Hofman PAM, Hendriks MPH, Kessels RPC, Willems FMJ, de With PHN, Zinger S, Jansen JFA. Brain resting-state networks in adolescents with high-functioning autism: analysis of spatial connectivity and temporal neurodynamics. Brain Behav. 2018;17:e00878.

11. Best JR, Miller PH. A developmental perspective on excecutive function. Child Dev. 2010:81:1641-60.

12. Bradley BP, Mogg K, Millar NH. Covert and overt orienting of attention to emotional faces in anxiety. Cogn Emotion. 2000;14:789-808.

13. Callejas A, Lupianez J, Funes MJ, Tudela P. Modulations among the alerting, orienting and executive control networks. Exp Brain Res. 2005;167:27-37.

14. Constantino JN, Todd RD. Autistic traits in the general population: a twin study. Arch Gen Psychiatry. 2003;60:524-30.

15. Corbetta M, Shulman GL. Control of goal-directed and stimulus-driven attention in the brain. Nat Rev Neurosci. 2002;3:201-15.

16. Dalton KM, Nacewicz BM, Alexander AL, Davidson RJ. Gaze-fixation, brain activation, and amygdala volume in unaffected siblings of individuals with autism. Biol Psychiatry. 2007;61:512-20.

17. Demetriou EA, Lampit A, Quintana DS, Naismith SL, Song YJC, Pye JE, Hickie I, Guastella AJ. Autism spectrum disorders: a meta-analysis of executive function. Mol Psychiatry. 2018;23:1198-204.

18. Di Martino A, Shehzad Z, Kelly C, Roy AK, Gee DG, Uddin LQ, Gotimer K, Klein DF, Castellanos FX, Milham MP. Relationship between cinguloinsular functional connectivity and autistic traits in neurotypical adults. Am J Psychiatry. 2009;166:891-9.

19. Diamond A. Normal development of prefrontal cortex from birth to young adulthood: cognitive functions, anatomy, and biochemistry. In Struss DT, Knight RT, editors. Principles of Frontal Lobe Function. New York: Oxford University Press; 2002. p. 466-503.

20. Dziobek I, Bahnemann M, Convit A, Heekeren HR. The role of the fusiformamygdala system in the pathophysiology of autism. Arch Gen Psychiatry. 2010;67:397-405.

21. Erickson $\mathrm{Kl}$, Hillman $\mathrm{CH}$, Kramer AF. Physical activity, brain, and cognition. Curr Opin in Behav Sci. 2015:4:27-32.

22. Fan J, McCandliss BD, Sommer T, Raz A, Posner MI. Testing the efficiency and independence of attentional networks. J Cogn Neurosci. 2002;14:340-7.

23. Fan J, McCandliss BD, Fossella J, Flombaum JI, Posner MI. The activation of attentional networks. Neuroimage. 2005;26:471-9.

24. Fan J, Gu X, Guise KG, Liu X, Fossella J, Wang H, Posner MI. Testing the behavioral interaction and integration of attentional networks. Brain Cogn. 2009:70:209-20.

25. Fan J, Bernardi S, Dam NT, Anagnostou E, Gu X, Martin L, Park Y, Liu X, Kolevzon A, Soorya L, Grodberg D, Hollander E, Hof PR. Functional deficits of the attentional networks in autism. Brain Behav. 2012;2:647-60.

26. Farrant K, Uddin L. Atypical developmental of dorsal and ventral attention networks in autism. Dev Sci. 2016;19:550-63.

27. Fossella J, Sommer T, Fan J, Wu Y, Swanson JM, Posner PDW, MI. Assessing the molecular genetics of attention networks. BMC Neurosci. 2002;3:14.

28. Fuentes $\sqcup$, Campoy $G$. The time course of alerting effect over orienting in the attention network test. Exp Brain Res. 2008;185:667-72.

29. Gasper K, Clore GL. Attending to the big picture: mood and global versus local processing of visual information. Psychol Sci. 2002;13:34-40.

30. Griffanti L, Salimi-Khorshidi G, Beckmann CF, Auerbach EJ, Douaud G, Sexton CE, Zsoldos E, Ebmeier KP, Filippini N, Mackay CE, Moeller S, Xu J, Yacoub E, Baselli G, Ugurbil K, Miller KL, Smith SM. ICA-based artefact removal and accelerated $\mathrm{fMRI}$ acquisition for improved resting state network imaging. Neuroimage. 2014;95:232-47.

31. Hillman CH, Pontifex MB, Castelli DM, Khan NA, Raine LB, Scudder MR, Drollette ES, Moore RD, Wu C, Kamijo K. Effects of the FITKids randomized controlled trial on executive control and brain function. Pediatrics. 2014;134:e1063-71.

32. Hull JV, Dokovna LB, Jacokes ZJ, Torgerson CM, Irimia A, Van Horn JD. Resting-State functional connectivity in autism spectrum disorders: a review. Front Psychiatry. 2017;7:205.

33. Kane MJ, Bleckley MK, Conway AR, Engel RW. A controlled-attention view of working-memory capacity. J Exp Psychol Gen. 2001;130:169-83.

34. Kanwisher NG, McDermott J, Chun MM. The fusiform face area: a module in human extrastriate cortex specialized for face perception. J Neurosci. 1997;17:4302-11. 
35. Keehn B, Lincoln AJ, Müller R, Townsend J. Attentional networks in children and adolescents with autism spectrum disorder. J Child Psyc Psychiat. 2010;51:1251-9.

36. Keehn B, Müller R, Townsend J. Atypical attentional networks and the emergence of autism. Neurosci Biobehav Rev. 2013;37:164-83.

37. Keehn B, Shih P, Brenner LA, Townsend J, Müller R. Functional connectivity for an "Island of Sparing" in autism spectrum disorder: an FMRI Study of Visual Search. Human Brain Mapp. 2013;34:2524-37.

38. Ko HY, Lee WH, Won EK, Ban JJ, Jung DE, Kim Y. The reliability and validity of the Korean Version of the Autism-Spectrum Quotient. Psychiatry Investig. 2018;15:783-9.

39. Losh M, Adolphs R, Poe MD, Couture S, Penn D, Baranek GT, Piven J. Neuropsychological profile of autism and the broad autism phenotype. Arch Gen Psychiatry. 2009;66:518-26.

40. Matsuoka K, Uno M, Kasai K, Koyama K, Kim Y. Estimation of premorbid IQ in individuals with Alzheimer's disease using Japanese ideographic script (Kanji) compound words: Japanese version of National Adult Reading Test. P Psychiatry Clin Neurosci. 2006;60:332-9.

41. Micali N, Chakrabarti S, Fombonne E. The Broad Autism phenotype findings from an epidemiological survey. Autism. 2004:8:21-37.

42. Mosconi MW, Kay M, D'Cruz AM, Guter S, Kapur K, Macmillan C, Stanford LD, Sweeney JA. Neurobehavioral abnormalities in first-degree relatives of individuals with autism. Arch Gen Psychiatry. 2010;67:315-22.

43. Mosconi MW, Sweeny JA. Sensorimotor dysfunctions as primary features of autism spectrum disorders. Sci China Life Sci. 2015;58:1016-23.

44. Mosely RL, Ypma RJ, Holt RJ, Floris D, Chura LR, Spencer MD, Baron-Cohen S, Suckling J, Bullmore E, Rubinov M. Whole-brain functional hypoconnectivity as an endophenotype of autism in adolescents. Neuroimage Clin 2015:9:140-52

45. Mullane JC, Lawrence MA, Corkum PV, Klein RM, McLaughlin EN. The development of and interaction among alerting, orienting, and executive attention in children. Child Neuropsychol. 2016;22:155-76.

46. Nomi JS, Uddin LQ. Developmental changes in large-scale network connectivity in autism. Neuroimage Clin. 2015;7:732-41.

47. Nummenmaa L, Engell AD, von dem Hagen E, Henson RNA, Calder AJ. Autism spectrum traits predict the neural response to eye gaze in typical individuals. Neuroimage. 2011;59:3356-63.

48. Oldfield RC. The assessment and analysis of handedness: The Edinburgh inventory. Neuropsychologia. 1971;9:97-113.

49. Petersen SE, Posner MI. The attention system of the human brain: 20 years after. Annu Rev Neurosci. 2012;35:73-89.

50. Pierce K, Müller RA, Ambrose J, Allen G, Courchesne E. Face processing occurs outside the fusiform 'face area' in autism: evidence from functional MRI. Brain. 2001;124:2059-73.

51. Piven J, Palmer P. Psychiatric disorder and the broad autism phenotype: evidence from a family study of multiple-incidence autism families. Am J Psychiatry. 1999;156:557-63.

52. Power JD, Cohen AL, Nelson SM, Wig GS, Barnes KA, Church JA, Vogel AC, Laumann TO, Miezin FM, Schlagggar BL, Petersen SE. Functional network organization of the human brain. Neuron. 2011;72:665-78.

53. Pozuelos JP, Paz-Alonso PM, Castillo A, Fuentes $\sqcup$, Ruenda MR. Development of attention networks and their interactions in childhood. Dev Psychol. 2014:50:2405-15.
54. Raz A, Buhle J. Typologies of attentional networks. Nat Rev Neurosci. 2006;7:367-79.

55. Rueda MR, Pozuelos JP, Cómbita LM. Cognitive neuroscience of attention from brain mechanisms to individual differences in efficiency. AIMS Neuroscience. 2015;2:183-202.

56. Sato W, Sawada R, Uono S, Yoshimura S, Kochiyama T, Kubota Y, Sakihama M, Toichi M. Impaired detection of happy facial expression in autism. Sci Rep. 2017:7:13340

57. Schultz RT, Gauthier I, Klin A, Fulbright RK, Anderson AW, Volkmar F, Skudlarski P, Lacadie C, Cohen DJ, Gore JC. Abnormal ventral temporal cortical activity during face discrimination among individuals with autism and Asperger syndrome. Arch Gen Psychiatry. 2000;57:331-40.

58. Shechner T, Britton JC, Pérez-Edgar K, Bar-Haim Y, Ernst M, Fox NA, Leibenluft E, Pine DS. Attention biases, anxiety, and development: toward or away from threats or rewards? Depress Anxiety. 2012;29:282-94.

59. Spagna A, Martella D, Sebastiani M, Maccari L, Marotta A, Casagrande M. Efficiency and interactions of alerting, orienting and executive networks: the impact of imperative stimulus type. Acta Psychol. 2014;148:209-15.

60. Suzuki K, Sugihara G, Ouchi Y, Nakamura K, Tsuji M, Futatsubashi M, Iwata Y, Tsuchiya KJ, Matsumoto K, Takebayashi K, Wakuda T, Yoshihara Y, Suda S, Kikuchi M, Takei N, Sugiyama T, Irie T, Mori N. Reduced acetylcholinesterase activity in the fusiform gyrus in adults with autism spectrum disorders. Arch Gen Psychiatry. 2011;68:306-13.

61. Tang YY, Posner MI, Rothbart MK. Meditation improves self-regulation over the life span. Ann NY Acad Sci. 2014;1307:104-11.

62. Tavor I, Parker Jones O, Mars RB, Smith SM, Behrens TE, Jbabdi S. Task-free MRI predicts individual differences in brain activity during task performance. Science. 2016;352:216-20.

63. Waiter GD, Williams JHG, Murray AD, Gilchrist A, Perrett DI, Whiten A. A voxelbased investigation of brain structure in male adolescents with autistic spectrum disorder. Neuroimage. 2004;22:619-25.

64. Wakabayashi A, Baron-Cohen S, Wheelwright S, Tojo Y. The Autism-Spectrum Quotient (AQ) in Japan: A cross-cultural comparison. J Autism Dev Disord. 2006;36:263-70.

65. Weigelt S, Koldewyn K, Kanwisher N. Face identity recognition in autism spectrum disorders: a review of behavioral studies. Neurosci Biobehav Rev. 2012;36:1060-84.

66. Wilcox JA, Tsuang MT, Schnurr T, Baida-Fragoso N. Case-control family study of lesser variant traits in autism. Neuropsychobiology. 2003:47:171-7.

67. Xuan B, Mackie MA, Spagna A, Wu T, Tian Y, Hof PR, Fan J. The activation of interactive attentional networks. Neuroimage. 2016;129:308-19.

68. Yoshimura S, Sato W, Kochiyama T, Uono S, Sawada R, Kubota Y, Toichi M. Gray matter volumes of early sensory regions are associated with individual differences in sensory processing. Hum Brain Mapp. 2017;38:6206-17.

69. Zhao S, Uono S, Yoshimura S, Toichi M. Is impaired joint attention present in non-clinical individuals with high autistic traits? Mol Autism. 2015;6:67.

\section{Publisher's Note}

Springer Nature remains neutral with regard to jurisdictional claims in published maps and institutional affiliations.

Ready to submit your research? Choose BMC and benefit from

- fast, convenient online submission

- thorough peer review by experienced researchers in your field

- rapid publication on acceptance

- support for research data, including large and complex data types

- gold Open Access which fosters wider collaboration and increased citations

- maximum visibility for your research: over 100M website views per year

At $\mathrm{BMC}$, research is always in progress.

Learn more biomedcentral.com/submissions 